\title{
Acquired alopecia, mental retardation, short stature, microcephaly, and optic atrophy
}

\author{
R C M Hennekam, E G C M Renckens-Wennen
}

\begin{abstract}
We report on a female patient who had acquired total alopecia, short stature, microcephaly, optic atrophy, severe myopia, and mental retardation. A survey of published reports failed to show an identical patient, despite various similar cases.
\end{abstract}

\section{Case report}

The proband was the first child of a healthy 26 year old mother and non-consanguineous 37 year old father. The parents had had a total of five miscarriages. The father had two children from a later marriage. The parents and sibs did not wear glasses, had normal heights, and showed no signs of an ectodermal dysplasia.

Pregnancy and delivery were uneventful and at birth no anomalies were seen. At the age of 5 years her hair started to fall out and she was completely bald by the age of 8 years. She had severely retarded psychomotor development. She had had no specific illnesses, particularly no seizures or skin infections. Menarche was at 18 years, and she had regular menses thereafter. Physical examination at $\mathbf{4 2}$ years showed a friendly, retarded woman. Height was $150.3 \mathrm{~cm}$ ( $<3$ rd centile) and head circumference $50.1 \mathrm{~cm}(<3 \mathrm{rd}$ centile). She had fleshy nasal alae, deep nasolabial grooves, full lips, and downturned corners of the mouth (figure). There was no scalp hair, eyebrows, or eyelashes, virtually no pubic hair, but some axillary hair. Her skin, nails, breasts, and sweating pattern were normal. She had a partial dental prosthesis, probably because of former inadequate dental care.

Clinical Genetics Centre Utrecht, PO Box 18009, 3501 CA Utrecht, The Netherlands.

R C M Hennekam

Institute for the Mentally Retarded De Sterrenberg, Huis ter Heide, The Netherlands.

E G C M Renckens-Wennen

Correspondence to Dr Hennekam.

Received for publication 13 March 1990.

Accepted for publication 2 April 1990.
The remaining teeth were normal. She had severe myopia bilaterally ( -10 dioptres). Fundoscopy showed atrophic, pale discs. She had narrow hands with long fingers (total hand length $16.3 \mathrm{~cm}$ (3rd to 10th centile), middle finger length $7 \cdot 1 \mathrm{~cm}$ (25th centile), and small feet (length $21 \mathrm{~cm}, 3$ rd centile).

Chromosome analysis, using GTG banding, showed a normal female 46,XX karyotype. EEG, audiometry, and urinary metabolic screening gave normal results. Radiography of the skull showed no anomalies, especially no unerupted teeth.

\section{Discussion}

The present patient is compared with other relevant published cases in the table. Although close similarities can be seen, heterogeneity within this nosological group probably exists. ${ }^{2}$ Our patient resembles most the cases of Mosavy, ${ }^{1}$ Pfeiffer and Völklein, ${ }^{2}$ Baraitser et $a l,{ }^{7}$ and Benke and Hajianpour. ${ }^{8}$ The alopecia was congenital in all these reports. The patients reported by Baraitser $e t a l^{7}$ and Benke and Hajianpour ${ }^{8}$ did not have growth retardation, optic atrophy, or myopia. Schinzel ${ }^{13}$ and Van Gelderen ${ }^{14}$ each described a patient with mental retardation, alopecia, myopia, short stature, and microcephaly. Their patients had different facial features, contractures, and numerous skeletal anomalies. Optic atrophy together with growth retardation and acquired alopecia are features of the GAPO syndrome. ${ }^{15-17}$ However, patients with this condition are usually not retarded and have in addition pseudoanodontia, prominent scalp veins, and characteristic facial features. We conclude that our case probably has a different condition from the other reports. It represents possibly a distinct neuroectodermal disorder of unknown cause.

We thank Dr M Baraitser (London) and Dr R A Pfeiffer (Erlangen) for their help in studying this patient.

1 Mosavy SH. Universal alopecia and microcephaly in 4 siblings. $S$ Afr Med F 1975;49:172.

2 Pfeiffer RA, Völklein J. Congenital universal alopecia, mental deficiency, and microcephaly in two sibs. $\mathcal{F}$ Med Genet 1982;19:388-9.

3 Moyahan EJ. Familial congenital alopecia, epilepsy, mental 

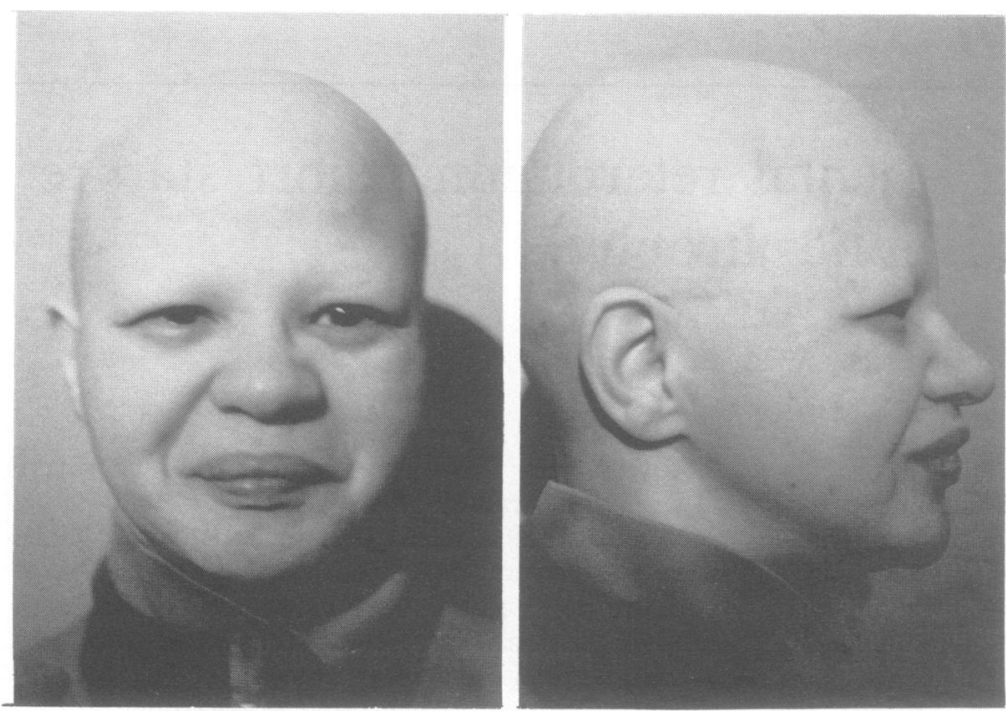

The patient at the age of 42 years.

Main differential diagnostic features compared with present patient.

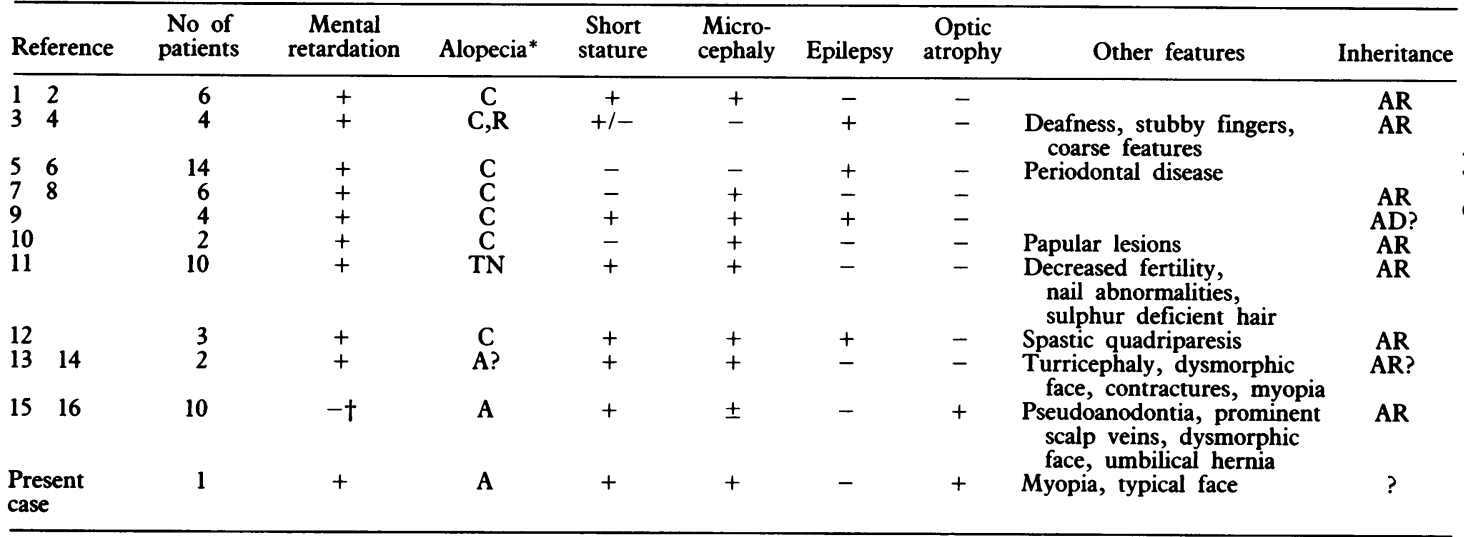

${ }^{*} \mathrm{C}=$ congenital or in first weeks of life, $\mathrm{R}=$ regrowing in infancy, $\mathrm{TN}=$ trichorrhexis nodosa, $\mathrm{A}=$ acquired.

tOne case reported with borderline intelligence. ${ }^{17}$

retardation with unusual electroencephalograms. Proc $R$ Soc Med 1962;55:11-2.

4 Perniola T, Krajewska G, Carnevale F, Lospalluti M. Congenital alopecia, psychomotor retardation, and convulsions in two sibs of a consanguineous marriage. F Inher Metab Dis 1980;3:49-53.

5 Shokeir MHK. Universal permanent alopecia, psychomotor epilepsy, pyorrhoea and mental subnormality. Clin Genet 1977;11:13-7.

6 Richieri-Costa A, Frota-Pessoa O. Atrichia, abnormal EEG, epilepsy, and mental retardation in two sisters. Hum Hered 1979;29:293-7.

7 Baraitser M, Carter CO, Brett EM. A new alopecia/mental retardation syndrome. F Med Genet 1983;20:64-75.

8 Benke PJ, Hajianpour MJ. Alopecia universalis-mental retardation is an autosomal recessive syndrome disorder. Am $\mathcal{F} \mathrm{Hum}$ Genet 1985;37:44A.

9 Hurst JA, Van Haeringen A, Baraitser M. A dominantly inherited syndrome of microcephaly, sparse hair, mental retardation, and seizures. $\mathcal{F}$ Med Genet 1989;26:597A.

10 Del Castillo V, Ruiz-Maldonado R, Carnevale A. Atrichia with papular lesions and mental retardation in two sisters. Int $\mathcal{F}$ Dermatol 1974;13:261-5.
11 King MD, Gummer CL, Stephenson JBP. Trichothiodystrophyneurotrichocutaneous syndrome of Pollitt: a report of two unrelated cases. F Med Genet 1984;21:286-9.

12 Wessel HB, Barmada MA, Hashida J. Congenital alopecia, seizures and psychomotor retardation in three siblings. Pediatr Neurol 1987;3:101-7.

13 Schinzel A. A case of multiple skeletal anomalies, ectodermal dysplasia and severe growth and mental retardation. Helv Paediatr Acta 1980;35:243-51.

14 Van Gelderen HH. Syndrome of total alopecia, multiple skeletal anomalies, shortness of stature and mental deficiency. $A m \mathcal{F}$ Med Genet 1982;13:383-7.

15 Tipton RE, Gorlin RJ. Growth retardation, alopecia, pseudoanodontia and optic atrophy - the GAPO syndrome: report of a patient and review of the literature. Am f Med Genet 1984;19: 209-16.

16 Manouvrier-Hanu S, Largillière C, Farriaux JP. Le syndrome G.A.P.O. A propos d'un nouveau cas. $\mathcal{F}$ Genet Hum 1988;36: 373-8.

17 Shapira J, Yatziv S, Deckelbaum R. Growth retardation, alopecia, pseudoanodontia and optic atrophy. Syndrome Ident 1985;8:14-6. 